Original Research Paper

\title{
Development of Improved Preventive and Treatment Strategies for Controlling of Toxoplasmosis in Saudi Arabia
}

\author{
${ }^{1,2}$ Alaa B. Ismael, ${ }^{3,4}$ Ayman A. Swelum and ${ }^{5}$ Mohammed A. Nassan \\ ${ }^{I}$ Department of Medical Biotechnology, Faculty of Applied Medical Sciences, \\ Taif University, Turrabah, KSA, Saudi Arabia \\ ${ }^{2}$ Department of Animal Medicine, Faculty of Veterinary Medicine, Zagazig University, Zagazig,, Egypt \\ ${ }^{3}$ Department of Animal Production, College of Food and Agriculture Sciences, \\ King Saud University, Riyadh, KSA, Saudi Arabia \\ ${ }^{4}$ Department of Theriogenology, Faculty of Veterinary Medicine, Zagazig University, Zagazig, Egypt \\ ${ }^{5}$ Department of Pathology, Faculty of Veterinary Medicine, Zagazig University, Zagazig, Egypt
}

Article history

Received: 27-04-2016

Revised: $15-05-2016$

Accepted: 14-06-2016

Corresponding Author:

Alaa B. Ismael

Department of Medical

Biotechnology, Faculty of

Applied Medical Sciences-

Turrabah, Taif University,

21995, KSA, Saudi Arabia

Email: alismael7@gmail.com

\begin{abstract}
Toxoplasmosis causes severe public health problems and has great veterinary and economic importance worldwide. The present study aims mainly to develop an improved preventive and treatment program for controlling toxoplasmosis in sheep and goats. This study was performed on sheep and goats farm containing 357 animals (300 sheep and 57 goats). This farm had a large numbers of barren ewes, history of abortions (below 4 months), stillbirths, malformations and neonatal losses. Blood samples were collected to determine humeral antibody responses and prevalence of toxoplasmosis. Sections of normal and abnormal tissues were fixed using $10 \%$ buffered formalin for histopathological examination. Different and new drug regimens and strategies were used for controlling toxoplasmosis. Sixty-four out of 357 sheep and goats were clinically affected with $17.9 \%$ overall morbidity rate. These animals showed certain clinical symptoms of toxoplasmosis, such as abortions and stillbirth. The seroprevalence rate was $15.4 \%$. The titers of ELISA were high before treatment in positive cases while after treatment the titers were decreased for certain level that continued to the end of study. The field treatment revealed that the affected sheep and goats treated with camel lactoferrin (cLf) and chemotherapy combination regimen significantly reduced the overall severity of toxoplasmosis with reduction in IgG titers better than those treated with chemotherapy alone (Pyrimethamine and sulfamethazine) or cLf alone. In conclusion, cLf and chemotherapy combination regimen was success in control of toxoplasmosis in small ruminants.
\end{abstract}

Keywords: Toxoplasmosis, Diagnosis, Sheep and Goats, Camel Lactoferrin, Treatment, Control

\section{Introduction}

Toxoplasmosis is a global zoonotic disease caused by the apicomplexan coccidian Toxoplasma gondii, an obligatory intracellular protozoan that can infect humans and all warm-blooded animals. This wide-ranging host makes it one of the most successful protozoan parasites (Radostits et al., 2007). In human, it is a dangerous disease in immunocompromised and immunosuppressed patients and congenitally infected children (Tenter et al., 2000; Montoya and Liesenfeld, 2004). Primary infection in pregnant seronegative women can cause neonatal death, abortion and severe congenital abnormalities, such as hydrocephalus, blindness, chorioretinitis and mental retardation (Petersen et al., 2001). On the other side, toxoplasmosis in animals has great economic importance worldwide because it can cause stillbirth, abortions and neonatal loss especially in sheep and goats (Buxton, 1998; Buxton et al., 2007). Moreover, viable $T$. gondii tissue cysts inside raw or undercooked meat of sheep and goats may be important sources of infection to humans and carnivores (Dubey, 2009). 
Although several studies of human toxoplasmosis were carried out in Kingdom of Saudi Arabia (Al-Harthi et al., 2006; Tonkal, 2008; Al-Mohammad et al., 2010; Bin Dajem and Almushait, 2012), a little data is available about the $T$. gondii prevalence in small ruminants under field condition in that country (Sanad and Al-Ghabban, 2007; Al-Mufarrej et al., 2011). Serological diagnosis considers the most commonly approach used to define the stage of infection, whether current, recent, or past (Nagaty et al., 2009).

Despite the seriousness of this disease, there are no effective commercial vaccines to combat it today. Indeed, a live attenuated Toxoplasma tachyzoites S48 vaccine is previously available and it can partially $(60 \%)$ protect pregnant sheep against toxoplasma infection (Buxton et al., 1991), but now it is difficult to manufacture because it has a short shelf life. Interestingly, we succeeded in development of a potent, successful and effective vaccine against toxoplasmosis that provides highly significant protection against congenital and acquired $T$. gondii infection in female OF1 mice (more than 96\% protection) (Ismael et al., 2006) and in sheep (90\% protection) (Mévélec et al., 2010). This vaccine is currently in the approval period and this work was realized in France. The absence of effective commercial vaccine invites the need to develop an improved preventative and treatment strategies for controlling toxoplasmosis.

Chemotherapy as antibiotics and/or sulphonamides are commonly used for treatment of toxoplasmosis in farm animals and human. In addition to antibiotics residues, the antibiotic therapy has numerous complications as direct toxicity, hypersensitivity, superinfections and antibiotic-induced immunosuppression (Adesiyun et al., 2007). This is highlighting the need for a new strategy for non-antibiotic therapy using novel immunomodulators. We succeed in purification and characterization of camel lactoferrin (cLf) from camel milk whey (Ismael et al., 2013). We proved that cLf is a potent natural antimicrobial and novel immunomodulator agent (Ismael et al., 2013). The present study aimed at, (i) determination of the occurrence of toxoplasmosis in small ruminants in studied farm (ii) make confirmatory diagnosis of toxoplasmosis in abortive small ruminants and (iii) comparison of different and new drug regimens and strategies for controlling toxoplasmosis.

\section{Material and Methods}

\section{History of Animals and Location}

This study was performed on sheep and goats farm containing 357 animals (300 sheep and 57 goats) and located in Riyadh region, KSA. This farm had a large numbers of barren ewes, history of abortions (below 4 months), stillbirths, malformations and neonatal losses. The animals had been reared under similar management, feeding systems and environmental conditions.

\section{Clinical Examination}

Animals were subjected to general clinical examination including pulse, temperature, respiration, mucous membrane color and others. All managements of the animals and the sample collections were in agreement with the rules for the animal's welfare and those of the concerned ethical authorities.

\section{Samples}

\section{Blood Samples}

The selected animals were subjected to blood collection via Jugular vein into plain vacutainer tubes. The blood samples were centrifuged at $3000 \mathrm{rpm} / 15 \mathrm{~min}$ for separation the serum that stored at $-20^{\circ} \mathrm{C}$ into $1.5 \mathrm{~mL}$ Eppendorf tubes until assay.

\section{Tissue Samples}

Sections of normal and abnormal placenta, uterus, liver, fetus, lung and trachea tissues were collected just after abortion or death and fixed in $10 \%$ formalin buffer for histopathological examination.

\section{Diagnosis of Toxoplasmosis}

\section{Ultrasonography}

The animals were subjected to full ultrasonography reproductive examination using multi-frequency linear trans-rectal probe (Prosound 2, Model UST-660-7.5, Aloka, Japan).

\section{Measurement of Humeral Antibody Responses to Natural Infection by Enzyme-Linked Immunosorbent Assay (ELISA)}

The antigen-specific IgG antibodies levels in serum samples were identified pre and post-treatment as previously described (Ismael et al., 2003). The TAg of $T$. gondii at $10 \mu \mathrm{g} \mathrm{mL}^{-1}$ was used to coat micro titer plates. The antigen-specific antibody titer is given as the reciprocal of the highest dilution producing an absorbance (OD) that was 2.5-fold greater than that of control serum at the same dilution. Results were expressed as the means of titers \pm Standard Deviations (SD).

\section{Histopathological Examinations}

A gross necropsy was performed on the placenta and aborted fetus. The fixed tissues were embedded in paraffin then sectioned by microtome. The resulted sections were stained with Hematoxylin-Eosin (HE) stain. 


\section{Field Treatment and Synergy Trials}

The affected sheep and goats were divided into 7 groups based on the clinical manifestations, 4 groups of 10 sheep and 3 groups of 8 goats (Table 3 and 4). Group I received no treatment and used as a control group. Group II was intramuscularly injected with Pyrimethamine $(100 \mathrm{mg} / \mathrm{kg} / 3$ days, then $50 \mathrm{mg})+$ sulfamethazine or sulfadiazine $(73 \mathrm{mg} / \mathrm{kg}$ for 3 days then $100 \mathrm{mg}$ ) (Radostits et al., 2007). Group III was treated with $\operatorname{cLf}(7 \%, 10 \mathrm{~mL} / 50 \mathrm{~kg})$, per Os, for 3-5 days of three periods with an interval of 5 days. Group IV received Pyrimethamine, sulfadiazine and cLf combinations regimen. The infected goats received the same therapeutic regimen of groups I, III and IV in sheep. All treated sheep and goats were examined daily for monitoring any clinical improvement. Sera samples were collected several times pre-, during and posttreatment for serological examination. The total treatment period was 25 days. The predisposing factors were monitored and controlled.

\section{Statistical Analysis}

The Statistical Products and Service Solutions program was used for all analysis. Comparisons among groups were tested using the using the $\chi^{2}$ (Chi-square) test. A difference was considered to be a statistically significant at $\mathrm{p}<0.05$.

\section{Results}

\section{Clinical Findings and Ultrasonography}

Clinical summary of the animals before and after treatment was illustrated in Table 1. Clinical reproductive examination of barren ewes revealed normal genital tract and no any abnormalities or pathology in reproductive tract (Fig. 1). Additionally, $15 \%$ of animals diagnosed as pregnant at day 23 post insemination (Fig. 2) was diagnosed non-pregnant (aborted) at day 60 post insemination. Sixty-four out of 357 sheep and goats were clinically affected (Table 1) with $17.9 \%$ overall morbidity rate. These animals showed certain clinical symptoms of toxoplasmosis, such as abortions in different stages especially in midgestation $(n=35)$ (Fig. 3), stillbirth $(n=9)$ (Fig. 4), malformation $(n=2)$ (Fig. 5) and neonatal loss. In addition, fever and other systemic signs were observed on 7 out 64 clinically affected animals $(10.9 \%)$. Two cases (goats) out of 64 were died with $3.13 \%$ case fatality rate. The post-mortem findings in dead animals revealed septicemia (Fig. 6). A gross necropsy was performed on the aborted fetus and placenta. The abdominal cavity was usually filled with fluid tinged with blood. The placenta was purple-gray in color and the cotyledons were pale tan and friable, with a gritty texture as though mineralized.

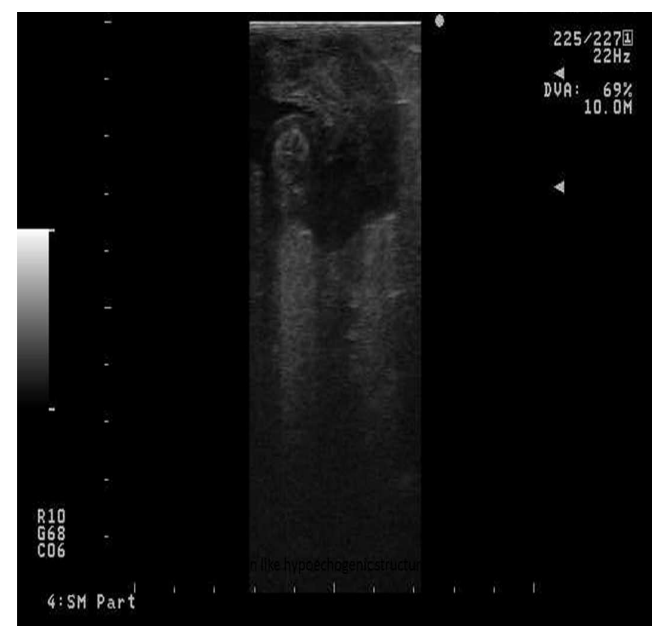

Fig. 1. Non pregnant uterus appeared horn like hypoechogenic structure using transrectal probe

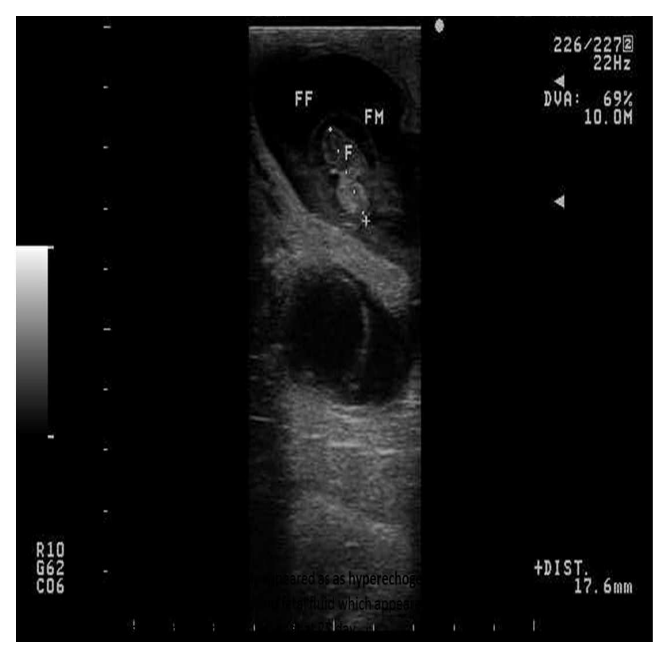

Fig. 2. Pregnant uterus had fetus which appeared as as hyperechogenic structure surrounded by fetal membrane and fetal fluid that appeared as anechoic structure using transrectal probe in pregnant goat at 23 day

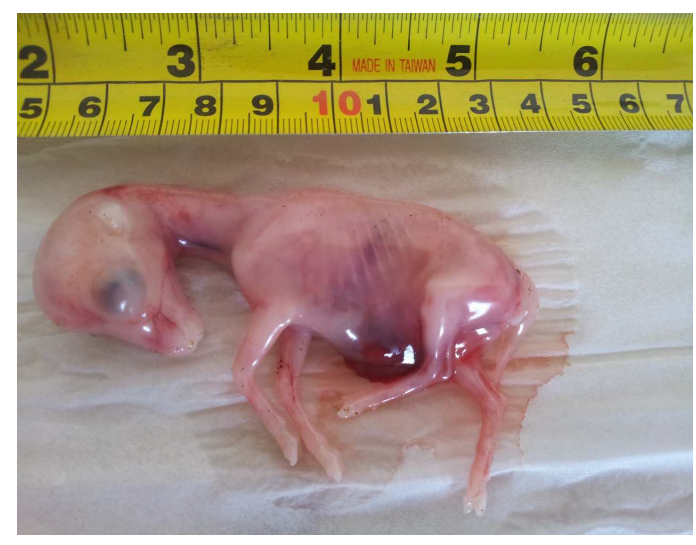

Fig. 3. Abortion due to toxoplasmosis in sheep 
Results of ELISA in Naturally Infected Animals by Toxoplasmosis Pre- and Post-Treatment

Analysis of serum antibody responses in naturally infected sheep and goats elicits serum IgG responses (Table 2). The IgG responses varied from strong positives, weak positive, suspected cases to negatives cases (Table 2 ). The seroprevalence rate was $15.4 \%$. The titers of ELISA were high before treatment in positive cases while after treatment the titers were decreased for certain level (weak) that continued to the end of study (Table 3 and 4).

\section{Histopathological Results}

Large numbers of small basophilic to amphophilic bradyzoites were detected in tissue cyst in the heart without prominent inflammatory reaction (Fig. 7 and 8). Microscopic examination of aborted fetus tissues and placenta indicated sign of necrotic placentitis. Diffuse edema with a population of mononuclear and segmented leukocytes was detected throughout the amnion of the placenta. Necrosis along the chorion and basophilic granular debris, supposed to be mineralization. Histopathological examination of the cotyledon revealed multifocal, mineralized and necrotic lesions.

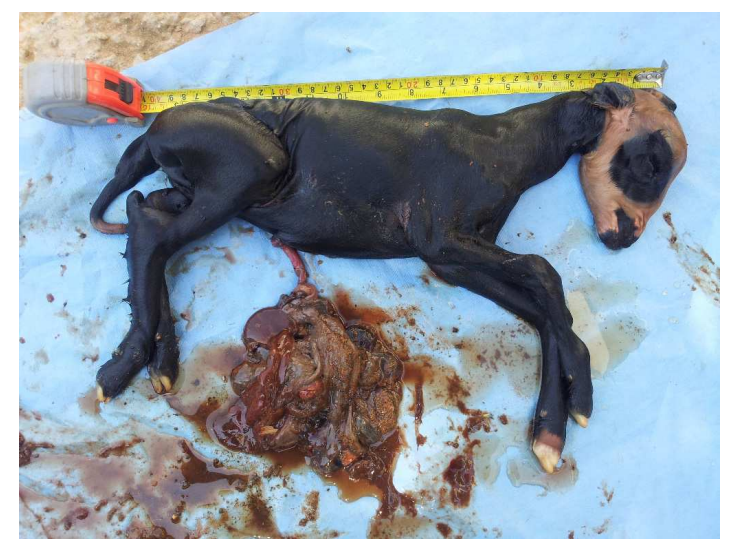

Fig. 4. Stillbirth due to toxoplasmosis in sheep

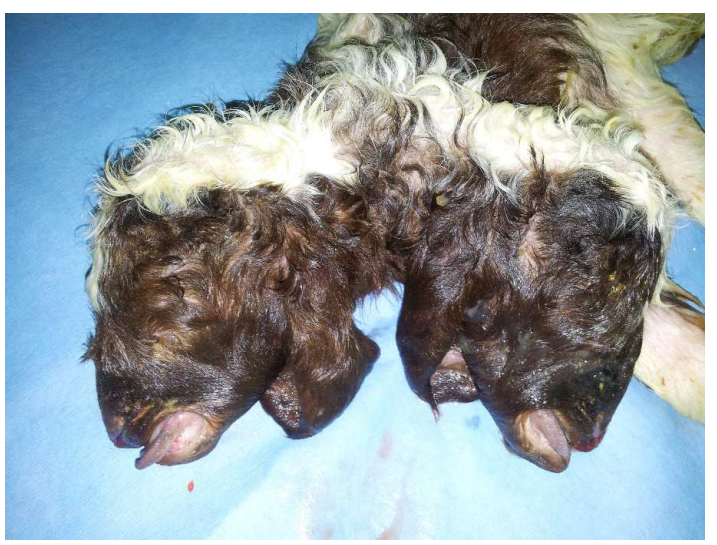

Fig. 5. Malformation due to toxoplasmosis in sheep

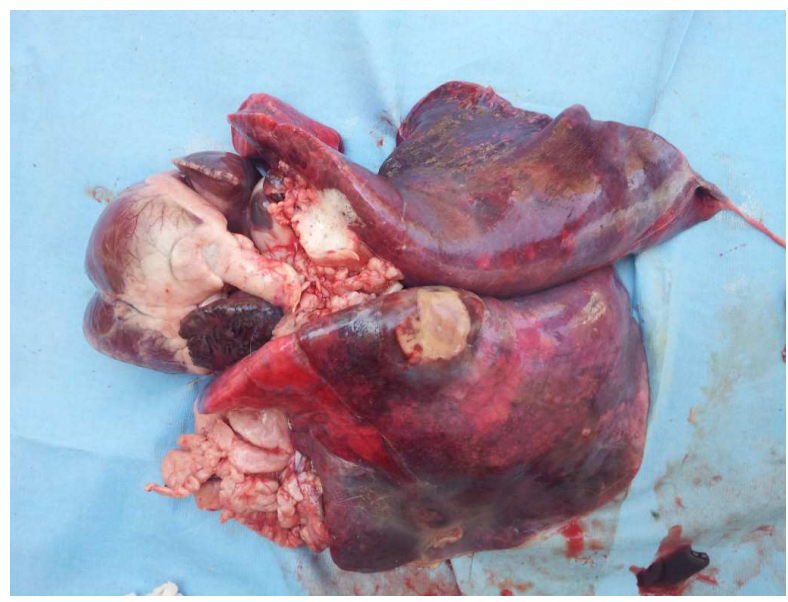

Fig. 6. Septicemia in post-mortum findings in sheep infected with Toxoplasma gondii

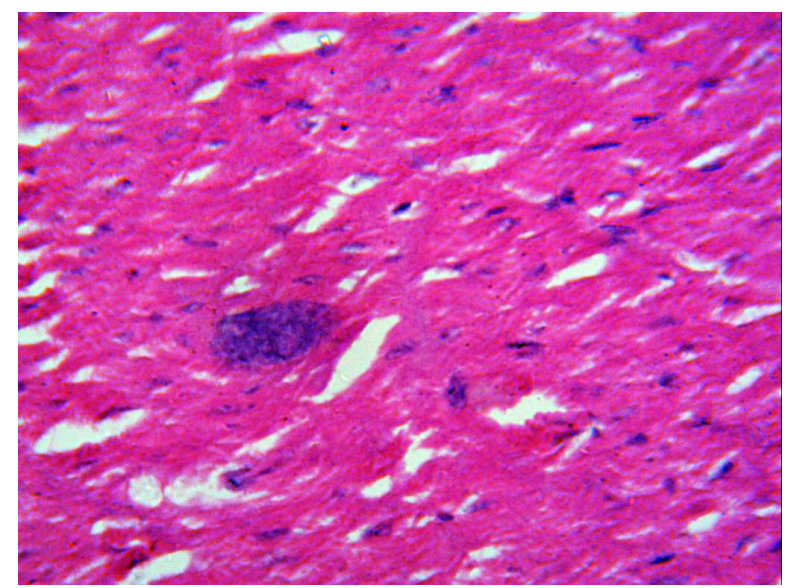

Fig. 7. Toxoplasma gondii cyst among cardiac myocytes with no significant inflammation associated with the infected cells. HE X300

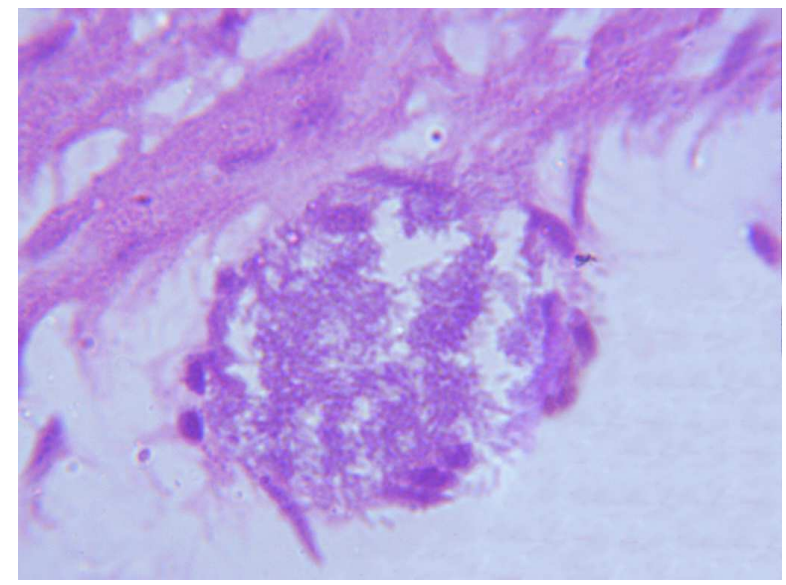

Fig. 8. Toxoplasma gondii cyst with greater detail of the small basophilic to amphophilic bradyzoites present in the cyst among myocytes. HE X3000 
Table 1. Clinical summary of the infected animals pre- and post treatment

\begin{tabular}{lllll}
\hline & Pre-treatment & & Post-treatment & \\
& - & & \\
Parameter & Sheep $(\mathrm{n}=40)$ & Goats $(\mathrm{n}=24)$ & Sheep $(\mathrm{n}=40)$ & Goats $(\mathrm{n}=24)$ \\
\hline Temperatures $^{\mathrm{a}}$ & $40 \pm 1$ & $41 \pm 1$ & $39 \pm 1$ & $40 \pm 1$ \\
Ruminations $^{\mathrm{b}}$ & $3 \pm 0$ & $3 \pm 1$ & $2 \pm 0$ & $2 \pm 1$ \\
Pulse $^{\mathrm{c}}$ & $98 \pm 3$ & $105 \pm 5$ & $76 \pm 5$ & $88 \pm 5$ \\
Respiration $^{\mathrm{d}}$ & $26 \pm 3$ & $39 \pm 4$ & $16 \pm 3$ & $27 \pm 5$ \\
Mucus membrane & Pale & Icterus & Normal & Normal \\
\hline
\end{tabular}

${ }^{\mathrm{a}}$ : Rectal temperatures in ${ }^{\circ} \mathrm{C} ;{ }^{b}$ : Ruminations per minute; ${ }^{\mathrm{c}}:$ Pulse in beats per minute; ${ }^{\mathrm{d}}$ : Respiration in breaths per minute; Results are expressed in mean $\pm \mathrm{SD}$ (Standard deviations).

Table 2. Results of ELISA in naturally infected sheep and goats by toxoplasmosis before treatment

\begin{tabular}{llllll}
\hline Item & Total cases & Strong positive & Weak positive & Suspect cases & Negative cases \\
\hline Number & $357^{\mathrm{a}}$ & $46^{\mathrm{b}}$ & $6^{\mathrm{c}}$ & $3^{\mathrm{d}}$ & 302 \\
$\%$ & 100 & 12.88 & 1.68 & 0.84 & 84.6 \\
Means \pm SD & - & $200 \pm 23$ & $80 \pm 7$ & $20 \pm 2$ & $10 \pm 3$ \\
\hline${ }^{\mathrm{a}}: 300(84 \%)$ sheep and $57(16 \%)$ goats; ${ }^{\mathrm{b}}: 31(67.4 \%)$ sheep and $15(32.6 \%)$ goats; ${ }^{\mathrm{c}}: 5(83.3 \%)$ sheep and $1(16.7 \%)$ goat; ${ }^{\mathrm{d}}: 3$
\end{tabular}

$(100 \%)$ sheep; Results are expressed as the means of titers \pm standard deviations (SD).

Table 3. Results of field treatment of toxoplasmosis in sheep

\begin{tabular}{|c|c|c|c|c|c|}
\hline \multirow[b]{2}{*}{ Group } & \multirow[b]{2}{*}{ No. } & \multirow[b]{2}{*}{ Therapeutic regimen } & \multirow[b]{2}{*}{$\begin{array}{l}\text { Clinical } \\
\text { improvement }\end{array}$} & \multicolumn{2}{|c|}{ ELISA results } \\
\hline & & & & Pre $^{c}$ & Post $^{\mathrm{c}}$ \\
\hline Group I & 10 & No treatment & $0 / 10(0 \%)^{\mathrm{a}}$ & $\mathrm{St}+\mathrm{ve}$ & $\mathrm{St}+\mathrm{ve}$ \\
\hline Group II & 10 & $\begin{array}{l}\text { Pyrimethamine }(100 \mathrm{mg} / \mathrm{kg} / 3 \text { days, then } 50 \mathrm{mg}) \\
+ \text { sulfamethazine or sulfadiazine }(73 \mathrm{mg} / \mathrm{kg} \\
\text { for } 3 \text { days then } 100 \mathrm{mg})\end{array}$ & $8 / 10(80 \%)^{b}$ & $\mathrm{St}+\mathrm{ve}$ & $\mathrm{W}+\mathrm{ve}$ \\
\hline Group III & 10 & cLf alone $(7 \%, 10 \mathrm{ml} / 50 \mathrm{~kg})$ & $7 / 10(70 \%)^{b}$ & $\mathrm{St}+\mathrm{ve}$ & $\mathrm{W}+\mathrm{ve}$ \\
\hline Group IV & 10 & cLf + Pyrimethamine and sulfadiazine & $10 / 10(100 \%)^{b}$ & $\mathrm{St}+\mathrm{ve}$ & $\mathrm{W}+\mathrm{ve}$ \\
\hline
\end{tabular}

${ }^{\mathrm{a}}$ : Significant difference with $^{\mathrm{b}}(\mathrm{p}<0.001)$ in the same column and non significant to that marked with ${ }^{\mathrm{a}}$. cLf: Camel lactoferrin. ${ }^{\mathrm{c}}:$ Pre and post- treatment. St + ve: Strong positive, $\mathrm{W}+$ ve: Weak positive.

Table 4. Results of field treatment of toxoplasmosis in goats

\begin{tabular}{|c|c|c|c|c|c|}
\hline \multirow[b]{2}{*}{ Group } & \multirow[b]{2}{*}{ No. } & \multirow[b]{2}{*}{ Therapeutic regimen } & \multirow[b]{2}{*}{$\begin{array}{l}\text { Clinical } \\
\text { improvement }\end{array}$} & \multicolumn{2}{|c|}{ ELISA results } \\
\hline & & & & Pre $^{\mathrm{c}}$ & $\operatorname{Post}^{\mathrm{c}}$ \\
\hline Group I & 8 & No treatment & $0 / 8(0 \%)^{\mathrm{a}} *$ & $\mathrm{St}+\mathrm{ve}$ & $\mathrm{St}+\mathrm{ve}$ \\
\hline Group II & 8 & cLf alone $(7 \%, 10 \mathrm{ml} / 50 \mathrm{~kg})$ & $7 / 8(87.5 \%)^{b}$ & $\mathrm{St}+\mathrm{ve}$ & $\mathrm{W}+\mathrm{ve}$ \\
\hline Group III & 8 & cLf + Pyrimethamine and sulfadiazine & $8 / 8(100 \%)^{b}$ & $\mathrm{St}+\mathrm{ve}$ & $\mathrm{W}+\mathrm{ve}$ \\
\hline
\end{tabular}

${ }^{a}$ : Significant difference with ${ }^{b}(p<0.001)$ in the same column and non significant to that marked with ${ }^{a}$ cLf: Camel lactoferrin. ${ }^{c}:$ Pre and post- treatment. St + ve: Strong positive, $\mathrm{W}+\mathrm{ve}$ : Weak positive. ${ }^{*}$ Two cases were died.

\section{Field Treatment}

It revealed that the affected sheep and goats treated with cLf and chemotherapy combination regimen significantly reduced the overall severity of toxoplasmosis with reduction in IgG titers better than those treated with chemotherapy alone (Pyrimethamine and sulfamethazine) or cLf alone (Table 3 and 4). The cLf alone was more effective in goats than in sheep (Table 3 and 4).

\section{Discussion}

This is the first study reporting the role of camel lactoferrin (cLf) in treatment of ovine and caprine toxoplasmosis in veterinary field. In the present study, the clinical picture of toxoplasmosis was appeared in 64 animals with $17.9 \%$ overall morbidity rate and $3.13 \%$ case fatality. Approximately similar results were described by Radostits et al. (2007). Abortions, stillbirth, malformation, neonatal loss and fever were observed in infected animals that indicated the appearance of acute phase of infection. Moreover, the systemic disease, with a slightly high case fatality rate occur in young goats (Radostits et al., 2007). Severity of infection is associated with the stage of gestation at which the animals become infected, the earlier in gestation, the more severity of infection (Dubey, 2009). Fetal death and resorption can be resulted from early infection while infection in the latter part of gestation may have no clinical effect with the lambs being born normal but infected and immune (Radostits et al., 2007).

The toxoplasmic infection was confirmed by macroscopic and microscopic pathological lesions. Although DNA detection and serology are useful tools, histopathology is important to establish a cause-effect 
association, because $T$. gondii can be passively transmitted transplacentally and fetuses can die of other causes (Dubey, 2009).

The seroprevalence rate was low $(15.4 \%)$ in our study, as detected by ELISA, that might be attributed to the presence of toxoplasmosis in this region from long time. The furthermost seroprevalence in sheep were found in Brazil (29.41\%) (Clementino et al., 2007) and southern Italy $(49.9 \%)$ (Vesco et al., 2007). The higher seroprevalence in southern Italy might be attributed to farm size and the presence of cats on the farm (Vesco et al., 2007). Various ELISA methods using recombinant, fractionated or crude antigens have been used to detect $T$. gondii antibodies in ovine sera that gave higher specificity in comparison with other serological tests (Dubey, 2009).

The field treatment revealed that the affected sheep and goats treated with $\mathrm{cLf}$ and chemotherapy combination regimen significantly reduced the overall severity of toxoplasmosis better than those treated with chemotherapy alone (Pyrimethamine and sulfamethazine or cLf alone. Moreover, the cLf alone may offer a good alternative treatment. The selection of treated animals was based on clinical findings because the animals in early acute infection showed clinical signs without appearance of antibody titers in serum. We succeed in purification and characterization of camel lactoferrin (cLf) from camel milk whey (Ismael et al. 2013). We proved that cLf is a novel immunomodulator and potent natural antimicrobial agent (Ismael et al. 2013). The role of Lf in sequestering iron from bacterial pathogens is one of the first antimicrobial properties discovered for $\mathrm{Lf}$ as in case of $S$. aureus which is known to be resistant to antimicrobials (Bhimani et al., 1999). This was believed to be the important antimicrobial action of Lf because apolactoferrin possessed antibacterial activity (Yamauchi et al., 1993). Spatial orientation and structural characteristics of the molecule are life-threatening factors in the functionality of an antimicrobial compound. Occurrence in several conditions strongly highlights the significance of the structure-function relationship in the multifunctionality of the Lf (Farnaud and Evans, 2005). It was later established that Lf's antimicrobial function has been attributed to an iron-independent mechanism and direct interaction with microbial surfaces (Farnaud and Evans, 2005; Valenti and Antonini, 2005). The cLf increased lymphocyte transformations and capacity to stimulate the proliferation of allogeneic lymphocyte. Moreover, it increased the production of proinflammatory cytokines (Zimecki et al., 2001; Ismael et al., 2013).

\section{Conclusion}

The results of current study record that cLf has a potent natural anti- $T$. gondii effect. This is the first study reporting the role cLf in treatment of ovine and caprine toxoplasmosis in veterinary field. This study recommended using the $\mathrm{cLf}$ in the treatment of various infectious diseases in humans and animals. Nevertheless, a lot of effort is required to obtain a better understanding of cLf activities.

\section{Acknowledgement}

The authors wish to extend their appreciation to the Vice President for Post-graduate Studies and Research, Taif University for providing research facilities.

\section{Funding Information}

This work is funded by the Deanship of Scientific Research, Taif University under the Fundamental Research Grant No. 1/435/3405.

\section{Author's Contributions}

Alaa B. Ismael: Contributed to conception and design, clinical diagnosis of infected animals, carrying out the field treatment, draft and critically revised manuscript with its submission.

Ayman A. Swelum: Contributed to acquisition, carrying out ultrasonography and ELISA, interpretation, data analysis and manuscript revision.

Mohammed A. Nassan: Performed the experiments of histopathological examinations and manuscript revision.

\section{Conflicts of Interest}

The authors declared no potential conflicts of interest with respect to the research, authorship and/or publication of this article.

\section{References}

Adesiyun, A.A., S. Stoute and B. David, 2007. Preprocessed bovine milk quality in trinidad: Prevalence and characteristics of bacterial pathogens and occurrence of antimicrobial residues in milk from collection centresm. Food Control, 18: 312-320. DOI: 10.1016/j.foodcont.2005.10.012

Al-Harthi, S.A., M.B. Jamjoom and H.O. Ghazi, 2006. Seroprevalence of Toxoplasma gondii among pregnant women in Makkah, Saudi Arabia. Umm Al-Qura Univ. J. Sci. Med. Eng., 18: 217-227.

Al-Mohammad, H.I., T.T. Amin, M.H. Balaha and M.S. Al-Moghannum, 2010. Toxoplasmosis among the pregnant women attending a Saudi maternity hospital: Seroprevalence and possible risk factors. Ann. Trop. Med. Parasitol., 104: 493-504. DOI: $10.1179 / 136485910 X 12786389891443$

Al-Mufarrej, S.I., M.F. Hussein, R.S. Aljumaah and A.R. Gar ElNabi, 2011. Toxoplasmosis in goats in Riyadh, Saudi Arabia. J. Ani. Vet. Adv., 10: 2779-2782. DOI: 10.3923/javaa.2011.2779.2782 
Bhimani, R.S., Y. Vendrov and P. Furmanski, 1999. Influence of lactoferrin feeding and injection against systemic staphylococcal infections in mice. J. Applied Microbiol., 86: 135-144.

DOI: $10.1046 / j .1365-2672.1999 .00644 . x$

Bin Dajem, S.M. and M.A. Almushait, 2012. Detection of Toxoplasma gondii DNA by PCR in blood samples collected from pregnant Saudi women from the Aseer region, Saudi Arabia. Ann. Saudi. Med., 32: 507-512. PMID: 22796740

Buxton, D., S.W. Maley, S.E. Wright, S. Rodger and P. Bartley et al., 2007. Toxoplasma gondii and ovine toxoplasmosis: New aspects of an old story. Vet. Parasitol., 149: 25-28.

DOI: $10.1016 /$ j.vetpar.2007.07.003

Buxton, D., K. Thomson, S. Maley, S. Wright and H.J. Bos, 1991. Vaccination of sheep with a live incomplete strain (S48) of Toxoplasma gondii and their immunity to challenge when pregnant. Vet. Rec., 129: 89-93. DOI: 10.1136/vr.129.5.89

Buxton, D., 1998. Protozoan infections (Toxoplasma gondii, Neospora caninum and Sarcocystis spp.) in sheep and goats: Recent advances. Vet. Res., 29: 289-310. PMID: 9689743

Clementino, M.M., M.F. Souza and V.F. Andrade Neto, 2007. Seroprevalence and Toxoplasma gondii-IgG avidity in sheep from Lajes, Brazil. Vet. Parasitol., 146: 199-203.

DOI: $10.1016 /$ j.vetpar.2007.02.036

Dubey, J.P., 2009. Toxoplasmosis in sheep-the last 20 years. Vet. Parasitol., 163: 1-14.

DOI: 10.1016/j.vetpar.2009.02.026

Farnaud, S. and R.W. Evans, 2005. Lactoferrin: A multifunctional protein with antimicrobial properties. Mol. Immunol., 40: 395-405.

DOI: 10.1016/S0161-5890(03)00152-4

Ismael, A.B., S.M. Abd El Hafez, M.B. Mahmoud, A.K.A. Elaraby and H.M. Hassan, 2013. Development of New strategy for non-antibiotic therapy: Dromedary camel lactoferrin has a potent antimicrobial and immunomodulator effects. Adv. Infect. Dis., 3:231-237. DOI: 10.4236/aid.2013.34034

Ismael, A.B., I. Dimier-Poisson, M. Lebrun, J.F. Dubremetz and D. Bout et al., 2006. Mic13Knockout of Toxoplasma gondii is a successful vaccine against chronic and congenital toxoplasmosis in mice. J. Infect. Dis., 194: 1176-1183. DOI: $10.1086 / 507706$

Ismael, A.B., D. Sekkai, C. Collin, D. Bout and M.N. Mévélec, 2003. The MIC3 gene of Toxoplasma gondii is a novel potent vaccine candidate against toxoplasmosis. Infect. Immun., 71: 6222-6228.

DOI: 10.1128/IAI.71.11.6222-6228.2003
Mévélec, M.N., C. Ducournau, A.B. Ismael, M. Olivier and E. Sèche et al., 2010. Mic1-3 Knockout Toxoplasma gondii is a good candidate for a vaccine against $T$. gondii-induced abortion in sheep. Vet. Res., 41: 49-61. DOI: 10.1051/vetres/2010021

Montoya, J.D. and O. Liesenfeld, 2004. Toxoplasmosis. Lancet, 363: 1965-1976. DOI: 10.1016/S0140-6736(04)16412-X

Nagaty, I.M., K.M. Ibrahim, A.H. Abdel-Tawab and A.E. Hassan, 2009. Diagnosis of Toxoplasma gondii by ELISA and PCR in mothers and their infants. J. Egypt. Soc. Parasitol., 39: 625-32. PMID: 19795769

Petersen, E., A. Pollak and I. Reiter-Owona, 2001. Recent trends in research on congenital toxoplasmosis. Int. J. Parasitol., 31: 115-44. DOI: 10.1016/S0020-7519(00)00140-5

Radostits, O.M., C.C. Gay, K.W. Hinchcliff and P.D. Constable, 2007. Diseases Associated with Protozoa. In: Veterinary Medicine: A Textbook of the Diseases of Cattle, Sheep, Pigs, Goats and Horses, Radostits, O.M. and H. Stanley (Eds.), Elsevier Saunders, Edinburgh, ISBN-10: 0702027774, pp: 1483-1540.

Sanad, M.M. and A.J. Al-Ghabban, 2007. Serological survey on toxoplasmosis among slaughtered sheep and goats in Tabouk, Saudi Arabia. J. Egypt. Soc. Parasitol., 37: 329-40. PMID: 17580587

Tenter, A.M., A.R. Heckeroth and L.M. Weiss, 2000. Toxoplasma gondii: From animals to humans. Int. J. Parasitol., 30: 1217-58. DOI: $10.1016 / \mathrm{S} 0020-7519(00) 00124-7$

Tonkal, A.M., 2008. PCR versus ELISA in diagnosis of human toxoplasmosis in Jeddah, Saudi Arabia. J. Egypt. Soc. Parasitol., 38: 707-714. PMID: 19209756

Valenti, P. and G. Antonini, 2005. Lactoferrin: An important host defense against microbial and viral attack. Cell Mol. Life Sci., 62: 2576-2587. DOI: $10.1007 / \mathrm{s} 00018-005-5372-0$

Vesco, G., W. Buffolano, S. La Chiusa, G. Mancuso and S.A. Caracappa et al., 2007. Toxoplasma gondii infections in sheep in Sicily, southern Italy. Vet. Parasitol., 146: 3-8. DOI: 10.1016/j.vetpar.2007.02.019

Yamauchi, K., M. Tomita, T.J. Giehl and R.T. Ellison, 1993. Antibacterial activity of lactoferrin and a pepsin-derived lactoferrin peptide fragment. Infect. Immun., 61: 719-728.

Zimecki, M., D. Stepniak, A. Szynol and M.L. Kruzel, 2001. Lactoferrin regulates proliferative response of human peripheral blood mononuclear cells to phytohemagglutinin and mixed lymphocyte reaction. Arch. Immunol. Ther. Exp., 49: 147-154. PMID: 11348019 